\title{
DEFINING EPIDEMIOLOGY OF EPIDERMOID CYST: A RETROSPECTIVE CASE STUDY AT RIMS RANCHI
}

KEY WORDS: epidermoid cyst , FNAC, submandibular

\section{Dr.Jayashree} Maity*

\section{Dr. Nasrin} Parwin

\section{Dr. Rabindra} Kumar Singh
Post-Graduate Student, Department of Pathology, RIMS, Ranchi. *Corresponding Author

Post-Graduate Student, Department of Pathology, RIMS, Ranchi.

Background: An epidermoid cyst is a benign cyst derived from the infundibulum or upper portion of a hair follicle, encapsulated in a thin layer of epidermis-like epithelium. They are common, painless lump can occur anywhere in body and usually do not require treatment, unless a person wants to have them removed due to cosmetic reasons, or if the cysts is infected. Material and method: It is a retrospective record based study, performed in department of Pathology RIMS, Ranchi. Study population included all cases those who came for fine needle aspiration cytology (FNAC) for the swelling over different areas on body, with some common clinical presentations of pain, mild pain or no pain and gradually increasing in size from January 2020-July 2021. Result: A total of 105 cases recorded with FNAC diagnosis of epidermoid cyst of which $62 \%$ were male, majority were adults of age group $21-30$ years $(33.33 \%)$ and most common site is submandibular region $19 \%$ followed by face $16 \%$ and periauricular region $13 \%$.Conclusion: Epidermoid cyst are common in adult males and more frequent on upper trunk.

\section{INTRODUCTION}

An epidermoid cyst is a slow-growing, painless lump. According to the British Association of Dermatology, epidermal cysts are common and not cancerous. Epidermoid cysts are typically filled with keratin and lipid-rich debris $[1,2]$. Although most commonly located on the face, neck, and trunk, epidermoid cysts can be found anywhere including the scrotum, genitalia, fingers, and cases within the buccal mucosa. Cysts may progress slowly and remain present for years. The term sebaceous cyst is commonly used; however, the term is a misnomer in that it does not involve the sebaceous gland. Epidermoid cysts develop within the infundibulum. Other common synonyms include infundibular cyst, epidermal cyst, and epidermal inclusion cyst. Although these cysts are recognized as benign lesions, rare malignancy can arise.[3][4][5] The term "dermoid" also has been used extensively to describe dermoid and epidermoid cysts; however, they are different entities. Dermoid cysts are common, diagnosed during infancy or early childhood, usually located superficially or in the anterior orbit, commonly mold bone, and rarely induce bone lysis. Conversely, epidermoid cysts can develop in any part of the body and are usually diagnosed later in life [6]. Although these cysts are recognized as benign lesions, rare malignancy can arise.These cysts may progress slowly for years $[7,8]$

It is rare to find these cysts before puberty. They are predominantly found in males. In the neonatal period, small epidermal cysts referred to as milium are common. Although, milium is epidermoid cyst occurring at all ages of life. Transient milia of the face is a very common problem, arising in approximately half of the newborns.

Physical examination generally reveals several millimeters to several centimeters of non-fluctuant, compressible mass. A central, dark comedone opening (punctum) is often described. Although epidermoid cysts usually remain asymptomatic, they may become inflamed as a result of the rupture of the cyst lining. A foul-smelling yellowish cheese-like material discharged from the lump may be described. Erythema, swelling, tenderness, palpation, pain, and fluctuation may occur suddenly, caused by inflammation. Inflamed cysts may be mistaken for a furuncle or carbuncle. Spontaneous or surgical drainage will facilitate the healing process.
Pathophysiology-The surface of your skin (epidermis) is made up of a thin, protective layer of cells that your body continuously sheds. Most epidermoid cysts form when these cells move deeper into your skin and multiply rather than slough off. Sometimes the cysts form due to irritation or injury of the skin or the most superficial portion of a hair follicle. The epidermal cells form the walls of the cyst and then secrete the protein keratin into the interior. The keratin is the thick, yellow substance that sometimes drains from the cyst. This abnormal growth of cells may be due to a damaged hair follicle or oil gland in your skin. Many people refer to epidermoid cysts as sebaceous cysts, but they're different. True sebaceous cysts are less common. They arise from the glands that secrete oily matter that lubricates hair and skin (sebaceous glands). Potential complications of epidermoid cysts include:

Inflammation. An epidermoid cyst can become tender and swollen, even if it's not infected. An inflamed cyst is difficult to remove.Your doctor is likely to postpone removing it until the inflammation subsides.

Rupture. A ruptured cyst often leads to a boil-like infection that requires prompt treatment.

Infection. Cysts can become infected and painful (abscessed).

Skin cancer. In very rare cases, epidermoid cysts can lead to skin cancer.

Differential diagnosis of epidermal inclusion cysts also include lipomas, neuromas, benign cutaneous growths, metastatic skin lesions, squamous cell carcinoma of the skin, basal cell carcinoma of the skin.

\section{MATERIAL AND METHOD}

This was a retrospective study, performed in the department of pathology, RIMS, Ranchi .Study population included 105 cases of swelling on different areas over body with complain of pain ,mild pain and painless over a period of January2020july2021. FNAC was done by puncturing the mass with a 22/23 gauge needle attached to $10 \mathrm{cc}$ syringe with full negative pressure ,moving it in quick strokes in various directions till aspirate appeared in the hub of the needle then it was 
withdrawn after equalizing the negative pressure. Air dried smears were stained with Leishman-Giemsa stain and alcohol fixed smears were stained with Hematoxyline and Eosin. Then the slides were observed under the light microscope.

Study procedure involed case reports having patient age, sex, site, clinical history with diagnosis based on cytological findings of the smears.

\section{RESULT}

In our present study of 105 cases 65 cases were male and 40 cases were female i.e. male to female ratio of $1.6: 1$. According to Zito et al. male -female ratio is 2:1.[1] Dutta et al. [8]reported a male to female ratio of 4.6: 1 and Jham et al.[9]reported a ratio of $3: 1$

\section{Table 1. sex wise incidence}

\begin{tabular}{|c|c|c|}
\hline sex & Number of cases & Percentage of cases \\
\hline male & 65 & $62 \%$ \\
\hline female & 40 & $38 \%$ \\
\hline total & 105 & $100 \%$ \\
\hline
\end{tabular}

In our study age 21-30 years present with majority of cases $35(33.33 \%)$.The epidermoid cyst can occur at any age, but it is more frequent in adulthood [10]. Zito et al reported that it occurs in a wide age range, from birth to 72 years but most typically arise in the third and fourth decades of life [11].

\section{Table 2. age wise incidence}

\begin{tabular}{|c|c|c|}
\hline Age distribution & Number of cases & Percentage of cases \\
\hline$<=10$ years & 3 & $2.8 \%$ \\
\hline $11-20$ years & 19 & $18.09 \%$ \\
\hline $21-30$ years & 35 & $33.33 \%$ \\
\hline $31-40$ years & 15 & $14.2 \%$ \\
\hline $41-50$ years & 17 & $16.2 \%$ \\
\hline $51-60$ years & 11 & $10.5 \%$ \\
\hline$>60$ years & 5 & $4.88 \%$ \\
\hline total & 105 & $100 \%$ \\
\hline
\end{tabular}

Table 3. site wise distribution

\begin{tabular}{|c|c|c|}
\hline $\begin{array}{c}\text { Various areas } \\
\text { of presentation }\end{array}$ & $\begin{array}{c}\text { Number of } \\
\text { cases }\end{array}$ & Percentage of cases \\
\hline scalp & 8 & $7.6 \%$ \\
\hline face & 17 & $16.19 \%$ \\
\hline submandibular & 20 & $19.04 \%$ \\
\hline periauricular & 14 & $13.33 \%$ \\
\hline Neck & 10 & $9.5 \%$ \\
\hline Chest & 8 & $7.6 \%$ \\
\hline back & 6 & $5.94 \%$ \\
\hline Breast & 2 & $1.9 \%$ \\
\hline Arm & 3 & $2.8 \%$ \\
\hline Finger & 3 & $2.8 \%$ \\
\hline Thigh & 2 & $1.9 \%$ \\
\hline buttock & 8 & $7.6 \%$ \\
\hline Legs & 2 & $1.9 \%$ \\
\hline genitals & 2 & $1.9 \%$ \\
\hline Total & 105 & $100 \%$ \\
\hline
\end{tabular}

In the present study submandibular region found to be most common site followed by periauricular and face. Janarthanam and Mahadevan described $7 \%$ of these cysts occur in the head and neck, oral cavity representing only $1.6 \%$ [12].The face, neck, periauricular area, and upper trunk are more commonly involved, but any part of the body including sites such as the nipple, genitalia, and palmoplantar area may be involved.

\section{CONCLUSION}

Epidermoid cysts are more common in males .It mostly occurs in adults, rare in children and most common site is submandibular region and face.

\section{REFERENCES}

1. Zito PM, ScharfR. Cyst, Epidermoid (Sebaceous Cyst) [Updated 2019 Dec 25] In: StatPearls [Internet]. Treasure Island (FL): StatPearls Publishing; 2020 Jan. PubMed

2. Cuda JD, Rangwala S, Taube JM. Benign Epithelial Tumors, Hamartomas, and Hyperplasias. In: Kang S, Amagai M, Bruckner AL, Enk AH, Margolis DJ, McMichael AJ, Orringer JS. Eds. Fitzpatrick's Dermatology. 9th edition. New York, United States:McGraw-Hill.

3. Kasahara R,TajiriR,Kobayashi K,Yao M,Kitami K, Squamous Cell Carcinoma Developing from a Testicular Epidermal Cyst: A Case Report and Literature Review. Case reports in urology.2019; [PubMed PMID:31019832]

4. Birge O,Erkan MM,Serin AN, Case report: epidermoid inclusion cyst of the clitoris as a long-term complication of female genital mutilation. Journal of medical case reports.2019 Apr 27; [PubMed PMID:31027516]

5. Kim SJ,Kim WG, Clinical and Imaging Features of a Ruptured Epidermal Inclusion Cyst in the Subareolar Area: A Case Report. The American journal of case reports.2019 Apr 24; [PubMed PMID:31015391]

6. Blanco G., Esteban R., Galarreta D., Saornil M.A. Orbital intradiploic giant epidermoid cyst.JAMA Ophthalmol.2001;119(5):771-773. [PubMed] [Google Scholar]

7 Curtin H.,Som P. 4th ed. Mosby; 2002. Head and Neck Imaging;pp. 2173-2183. [Google Scholar]

8. Dutta M., Saha J., Biswas G.S.C., Sen I., Sinha R. Epidermoid cysts in head and neck: our experiences, with review of literature. Indian J. Otolaryngol. Head Neck Surg. 2013;65(2013):14-21. [PMC free article] [PubMed] [Google Scholar]

9. Jham BC, Duraes GV, Jham AC, Santos CR. Epidermoid cyst of the floor of the mouth: a case report. J Can Dent Assoc. 2007;73:525-8. [PubMed] [Google Scholar]

10. Mendonca de J., Jardim E., Dos Santos C., Masocatto D., Quadros de D. Oliveira M. Epidermoid cyst: clinical and surgical case report. Ann. Maxillofac. Surg. 2017;7(1):151-154. [PMC free article] [PubMed] [Google Scholar]

11. Pires-Gonçalves L., Silva C.T., Costa-Dias S., Sousa-Mendes V. Testicular epidermoid cyst - Ultrasound and MR typical findings with macroscopy correlation.Int.Braz JUrol.201 1;37(4):534-535. [PubMed] [Google Scholar]

12. Janarthanam J., Mahadevan S. Epidermoid cyst of submandibular region. J. Oral Maxillofac. Pathol. 2012;16(3):435-437. [PMC free article] [PubMed] [Google Scholar] 